\title{
DISKUSI PARENTING TENTANG APLIKASI POLA ASUH ORANG TUA DALAM MENGHADAPI ANAK BALITA DI PAUD SPS KENANGA DUSUN GANDEKAN, PAJANGAN.
}

\author{
winarsih ${ }^{1}$, kuriasari pratiwi ${ }^{2}$, istri bartini ${ }^{3}$ \\ ${ }^{1,2}$ Kebidanan (DIII), Sekolah Tinggi Ilmu Kesehatan AKBIDYO, Indonesia \\ ${ }^{3}$ Kebidanan (S1), Sekolah Tinggi Ilmu Kesehetan AKBIDYO \\ e-mail: ${ }^{1}$ winarsihakbidyo@gmail.com, ${ }^{2}$ kurniasari pratiwi1@ gmail.com, ${ }^{3}$ istribartini@gmail.com
}

\begin{abstract}
ABSTRAK Keluarga adalah tempat pertama bagi pembentukan dan pendidikan anak. Melalui orangtualah anak akan belajar mengenai nilai-nilai dan norma. Parenting education adalah metode yang tepat bagi orang tua dalam pembentukan karakter anak. Parenting disini bukan hanya sekedar mengasuh anak, namun orang tua harus mendidik, membimbing dan melindungi setiap perkembangan anak. Al-Qur'an telah menjelaskan bagaimana mengasuh anak dalam Q.S At-Tahrim ayat 6 menerangkan bahwa posisi keluarga mempunyai tanggung jawab yang besar bagi perkembangan anak sehingga anak selamat dari api neraka. Dasar utama yang diletakkan oleh keluarga adalah dasar-dasar tingkah laku dan budi pekerti pada anak-anaknya. Tujuan diskusi parenting ini adalah agar ibu - ibu mendapatkan solusi tentang masalah yang dihadapi selama mengasuh anaknya dirumah. Metode yang digunakan diskusi interaktive dan tanya jawab langsung tentang bagaimana pola asuh orang tua. Kegiatan pengabdian yang telah dilaksanakan pada Hari selasa tanggal 13 Januari 2020 pukul 10.00 s/d selesai dengan metode diskusi interaktive dan tanya jawab pada orang tua sejumlah 11 ibu yang anaknya ada di PAUD SPS Kenanga di Dusun Gandekan berjalandengan lancar dan tampak peserta sangat antusias. dari hasil evalusi kegiatan dengan menggunakan angket dengan 8 pertanyaan seputar parenting pola asuh orangtua semua menjawab dengan setuju pada pertanyaan positive dan menjawab tidak setuju pada pertanyaan negative. Hasil wawancara dan diskusi langsung memang banyak orang tua yang masih kurang pas dalam berkomunikasi dengan anaknya, masih banyak bentakan dan teriakkan. Saran untuk pengabdian selanjutnya perlu menghadirkan suami sebagai sosok ayah.
\end{abstract}

\section{Kata Kunci : Diskusi Parenting ; Pola Asuh}

ABSTRACT The family is the first place for children's formation and education. It is through parents that children will learn about values and norms. Parenting education is the right method for parents in shaping a child's character. Parenting here is not just caring for children, but parents must educate, guide and protect each child's development. Al-Qur'an has explained how to care for children in Q.S At-Tahrim verse 6 explains that the position of the family has a great responsibility for the development of the child so that the child survives the hellfire. The main foundation laid by the family is the basics of behavior and character in their children. The purpose of this parenting discussion is for mothers to get solutions about the problems faced while caring for their children at home. Method is interactive discussions and direct questions and answers about how parents take care. Community service activities carried out on Tuesday January 132020 at 10:00 to finish with interactive discussion and question and answer method for parents of 11 mothers whose children are in PAUD SPS 
Kenanga in Gandekan Hamlet, run smoothly and appear to be participants very enthusiastic. from the evaluation of activities using a questionnaire with 8 questions about parenting parenting parents all answered by agreeing on positive questions and answering disagreeing to negative questions. The results of interviews and direct discussions are indeed many parents who are still less fit in communicating with their children, there are still many screaming and shouting. Suggestions for further devotion need to present the husband as a father figure.

Keywords: Parenting Discussion; Parenting

\section{Pendahuluan}

Pendidikan diawali dari keluarga. Keluarga adalah tempat pertama bagi pembentukan dan pendidikan anak. Orang tua dan rumah adalah sekolah pertama yang dikenal oleh anak, karena peran orang tua disini sangatlah penting. Melalui orangtualah anak akan belajar mengenai nilai-nilai dan norma sebelum anak memasuki jenjang prasekolah yaitu pendidikan PAUD maupun pendidikan sekolah dasar. Orang tua harus memiliki bekal mengenai berbagai macam informasi tentang pendidikan anak. Orang tua harus memberikan tauladan yang baik bagi anak-anaknya, karena anak usia dini adalah peniru yang ulung. Anak akan belajar melalui tahapan imitasi yaitu meniru. Apa yang dilihat dan didengar anak akan ditiru oleh anak. Jadi orang tua harus lebih berhati-hati dalam perilaku maupun perkataan.

Parenting education adalah metode yang tepat bagi orang tua dalam pembentukan karakter anak. Parenting disini bukan hanya sekedar mengasuh anak, namun orang tua harus mendidik, membimbing dan melindungi setiap perkembangan anak. Parenting educarion sendiri memiliki pengertian yaitu program pendidikan pengasuhan yang dilakukan oleh lembaga untuk meningkatkan kualitas kepengasuhan dan tercapainya visi-misi. Manfaat yang diperoleh dari parenting education yaitu menambah wawasan dan pengetahuan orang tua dalam hal pengasuhan anak sesuai dengan usia, karakter dan perkembangannya.

Usia dini merupakan masa dimana seorang anak senang bermain untuk menumbuhkan daya kreativitasnya. Namun akhir-akhir ini seorang anak cenderung lebih mengenal gadget dari pada bermain dengan kawan sebayanya. Hal ini disebabkan oleh pola asuh orang tua yang telah mengenalkan gadget terhadap anak yang masih berusia dini, tanpa membatasi penggunaannya. Dalam mendidik anak sebaiknya orang tua memberikan arahan dengan memberi contoh, seperti orang tua tidak bermain gadget dihadapan anak. Karena anak usia dini cenderung meniru orang yang ada di lingkungan seekitarnya. Orang tua juga harus konsisten terhadap aturan yang sudah diberikan.

Seorang anak ibarat cerminan dari orang tuanya. Anak yang diasuh dengan pola asuh yang baik maka anak akan tumbuh menjadi pribadi yang baik. Sebaliknya, anak yang diasuh dengan pola asuh yang buruk akan tumbuh menjadi anak dengan pribadi yang buruk. Seorang anak yang ada dalam didikan orang tua yang broken home cenderung mempengaruhi pribadi anak tersebut. Anak yang dibiasakan disiplin sejak dini akan memiliki sifat disiplin sampai tumbuh dewasa kelak.

Pola pengasuhan anak bermacam-macam, ada pola asuh orang tua yang menggunakan otoriter, adapula pola asuh yang demokrasi. Selain itu ada juga 
pola asuh yang permisif. Pola asuh otoriter cenderung menerapkan standar yang mutlak yang harus dipenuhi, biasanya diiringi dengan ancaman-ancaman. Sedangkan pola asuh demokrasi lebih memprioritaskan kepentingan anak, namun juga tidak ragu dalam mengontrol anak. Sedangkan pola asuh permisif ini memberikan kesempatan pada anaknya untuk melakukan sesuatu tanpa pengawasan yang cukup dari orang tua. Adanya berbagai macam pola asuh sebagai orang tua harus dapat menerapkan pola asuh yang tepat pada anaknya. Misalnya menggunakan pola asuh demokrasi yang dapat menumbuhkan kreativitas anak namun tetap dalam pengawasan orang tua. Pola asuh yang demokrasi lebih baik diterapkan kepada anak dibandingkan dengan pola asuh otoriter dan permisif. Pola asuh otoriter memberikan kesan egois orang tua terhadap anaknya, akibatnya anak memiliki sikap penakut. Sedangkan, pola asuh yang permisif akan berakibat tumbuhnya sikap anak yang egois tidak mengindahkan aturan.

Al-Qur'an telah menjelaskan bagaimana mengasuh anak dalam Q.S AtTahrim ayat 6 yang berbunyi:

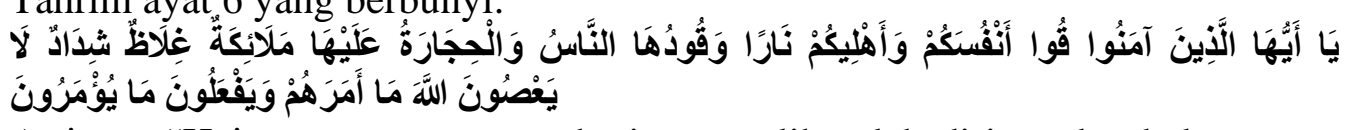

Artinya: "Hai orang-orang yang beriman, peliharalah dirimu dan keluargamu dari api neraka yang bahan bakarnya adalah manusia dan batu; penjaganya malaikat-malaikat yang kasar, keras, dan tidak mendurhakai Allah terhadap apa yang diperintahkan-Nya kepada mereka dan selalu mengerjakan apa yang diperintahkan".

Ayat diatas menerangkan bahwa posisi keluarga mempunyai tanggung jawab yang besar bagi perkembangan anak sehingga anak selamat dari api neraka. Maka dasar utama yang diletakkan oleh keluarga adalah dasar-dasar tingkah laku dan budi pekerti pada anak-anaknya. dalam kenyataannya yang sering kita temui orang tua yang gagal atau berhasil dalm membina, mengarahkan serta mendidik sebagai anak-anaknya sebagai anak sebagai anak yang baik dan berakhlak shaleh. Pola pengasuhan orang tua yang baik akan berdampak pada sikap anak saat dewasa. Dalam mendidik anak hendaknya orang tua mengerti apa yang dibutuhkan oleh anaknya. jangan jadikan anak-anak korban kesibukan orang tua. Didiklah anak sebaik-baiknya agar tidak menyesal nantinya, karena anak adalah aset dan investasi masa depan yang sangat berharga.

\section{Metode}

Metode yang digunakan pada kegiatan Pengabdian dengan judul Aplikasi Parenting tentang Pola Asuh Orangtua dalam menghadapi anaknya selama dirumah yaitu dengan metode dikriptif kualitatif melalui diskusi interaktif dan wawancara secara langsung dimana sasaranya adalah ibu - ibu sejumlah 11 orang yang anaknya di PAUD SPS Kenanga. Metode ini dirasa lebih cepat dalam mengetahui permasalahan ibu saat mengasuh anaknya dirumah. Metode diskusi secara kelompok dirasa lebih efektif digunakan karena orang tua menjadi aktif bertanya dan lebih paham bagaimana mengahadapi anaknya saat dirumah. Selain itu juga dengan diskusi kelompok menambah wawasan ilmu pengetahuan tentang pola asuh antar sesama ibu - ibu karena berbagai permasalahan yang berbeda - beda. Pedoman wawancara yang digunakan sangat sederhana yaitu pertanyaan seputar pola asuh dengan model pertanyaan sebagai berikut :

1. Bagaimana selama ini ibu dirumah dalam mengasuh anak ibu, adakah beberapa permasalahan yang ibu alami ? 
2. Bagaimana ibu menerapkan aturan keanak ibu?

3. Bagaimana ibu cara berkomunikasi dengan anak saat anak ibu diminta mengerjakan sesuatu hal atau melarang anak dalamsuatu hal misal anak jangan makan sambil lari atau hal lainya dikehidupan sehari - hari ?

4. Bagaimana ibu menerapkan sistem reword dan punishmen kepada anak?

5. Bagaimana model pola asuh ibu ke anak menurut ibu?

\section{Hasil dan Pembahasan}

Kegiatan Pengabdian masyarakat tentang Diskusi Parenting tentang Aplikasi Pola Asuh Orang Tua dalam menghadapi anak balita di PAUD SPS Kenanga dilaksanakan pada hari selasa, tanggal 13 Januari 2020, dimulai pukul $10.00 \mathrm{~s} / \mathrm{d}$ selesai, dimana sasaran adalah ibu - ibu yang anaknya di PAUD SPS Kenangan Dusun Gandekan, sejumlah 11 ibu.

Kegiatan ini berjalan lancar, sukses, dan seluruh peserta antusias. Karena konsep kegiatan dikemas dengan metode deskriptif kualitatif melalui diskusi dan tanya jawab secara langsung.

Dari hasil diskusi didapatkan beberapa pertanyaan dari ibu - ibu yang hadir yaitu :

a. Bagaimana komunikasi yang tepat saat anak mengulur waktu untuk mandi, sehingga membuat ortu harus berteriak - teriak memarahi anak

b. Bagaimana jika ortu ada masalah sehingga harus bertengkar didepan anak, Apakah hal tersebut boleh, kalau tidak strategi apa yang harus dilakukan

c. Bagaimana menghadapi anak yang suka mainan hape? kalau dilarang nangis. karena ortu tidak tega

d. Karena ibu bekerja adakah hal yang ahrus diutamakan ke anak, maksudnyamoment apa aja yang harusdikejar agar anak tetap mencintai kita sebagai ortu yang bekerja

e. Bagaimana mengatasi anak yang sering mengamuk menangis ( tantrum)

Setelah dilakukan wawancara mendalam dengan ibu - ibu dan menjawab semua pertanyaan ibu dapat disimpulkan bahwa kelemahan ibu - ibu ini terletak pada teknik komunikasi pada anak, hal ini diungkapkan oleh ibu - ibu kalau menyuruh anak harus teriak - teriak dan marah - marah agar anak tersebut mau misal mau segera mandi, atau memarahi kalau main hape tanpa diberikan alasan yang tepat yang bisa dipahami anak, alhasil anak malah semakin tidak patuh, menjawab semua perkataan ibu, tantrum mengamuk tidak jelas, dan menangis dengan kencang.

Selanjutnya masih banyak ibu - ibu yang jarang memberikan pujian pada anaknya hal ini terungkap saat anak menunjukkan prestasi ibu mengatakan mennaggapi hal itu boasa saja malah menyalahkan, harusnya memang seperti itu. Sehingga anak tidakmendapat motivasi dan semangat dari ibu.

Hal ini sesuai dengan hasil penelitian dari Yona Yolanda, Mudjiran bahwa komunikasi interpersonal orang tua dengan anak saat dirumah sangat penting untuk dibangun dengan baik seperti yang dijelaskan oleh shochib (2010) bahwa komunikasi keluarga telah berhasil menciptakan nilai - nilai moral yang akan dihayatkan dan diapresiasikan kepada anak - anaknya, yang sangat didukung oleh pola asuh orang yang berwibawa sehingga kepercayaan diri anak akan terpancar ke dalam diri anak.

Menurut Hurlock (1999) pola asuh yang tepat adalah demokratis dimana orang tua memberikan kebebasan kepada anak untuk memilih dan melakukan suatu tindakan dan pendekatan bersifat hangat.

Sejalan dengan hal diatas parenting style yang tepat menurut Baumrind (dalam santrock, 2004) adalah Autorative parenting dimana karakter orang tua 
lebih pada mendorong anak untuk mandiri namun tetap membuat batasan dan kontrol terhadap perilaku anak, memberikan kontrol tapi fleksibel, hangat, membuat tuntutan yang rasional, mendnegarkan pembicaraan anak, menghargai kedisiplinan membangun kepercayaan. sehingga perilaku anak yang terjadi adalah terlihat bahagia gembira dan memiliki kepercayaan diri.

\section{Penyajian gambar}

\section{1 dokumetasi diskusi 1}

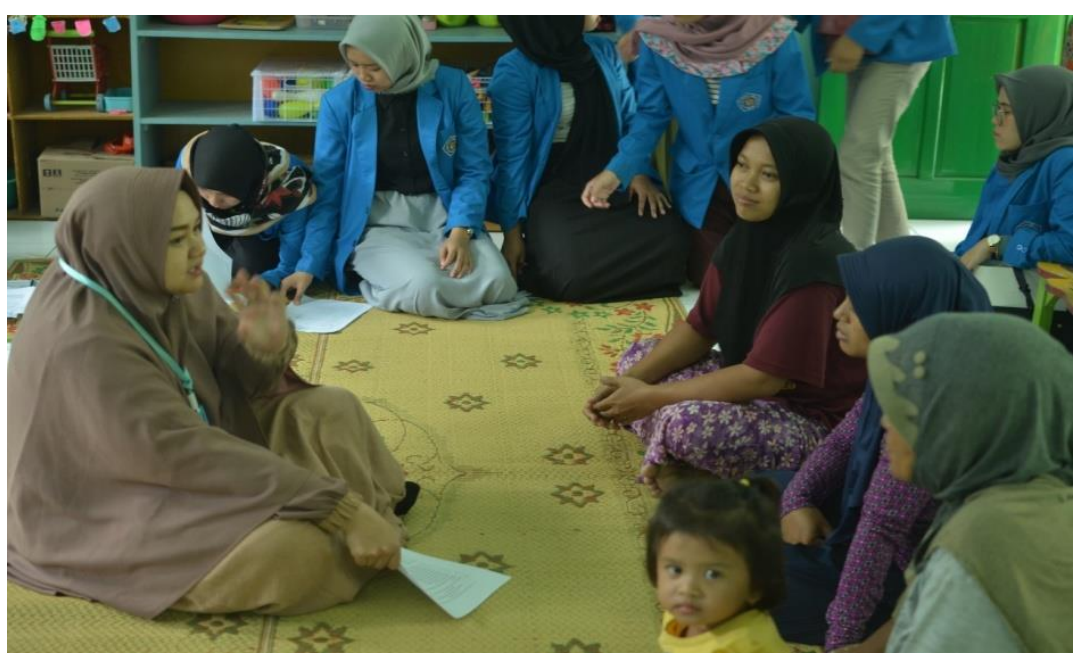

\section{2 dokumetasi diskusi 2}

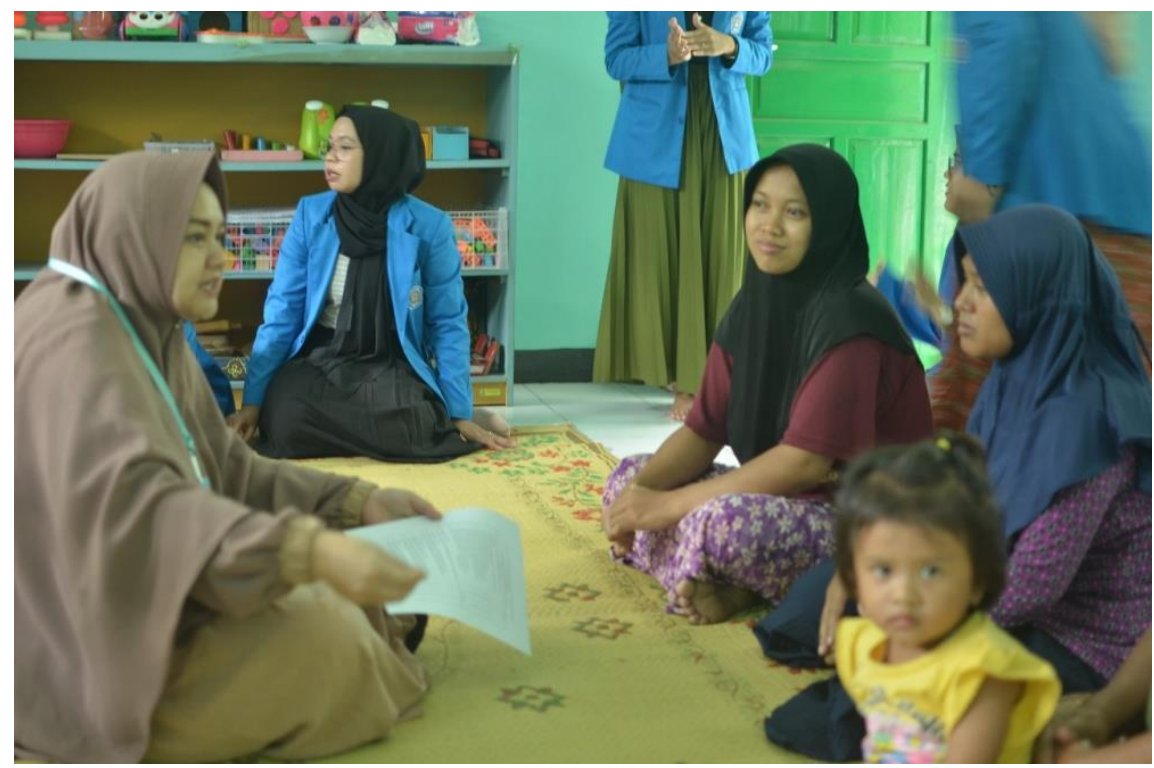




\section{Kesimpulan}

Secara keseluruhan rangkaian kegiatan Pengabdian Masyarakat dengan tema diskusi parenting tentang aplikasi pola asuh orang tua dalam menghadapi anak diusia balita di PAUD SPS Kenanga Desa Gandekan dimana sasarannya adalah $11 \mathrm{ibu}$. Kegiatan berjalan dengan lancar dan seluruh peserta antusias bertanya dan berdiskusi. Dapat disimulkan bahwa ibu - ibu banyak mengalami masalah dalam aspek komunikasi dan ibu tidak membiasakan diri memberikan pujian, sehingga pola asuh yang diterapkan tidak tepat.

Saran selanjutnya diskusi sebaiknya juga dihadirkan suami sebagai seorang ayah dan perlu ditambah media seperti booklet atau liflet berisi materi yang seputar pola asuh.

\section{Ucapan terimakasih}

Terimakasih saya sampaikan kepada berbagai pihak yang ikut berperan penting dalam kegiatan kegiatan pengabdian masyarakat dengan tema parenting ini, terutama pada dr. Musinggih Djarot Roujani Sp,Kj selaku Ketua STIKes AKBIDYO, ibu Suryatiningsih, SE selaku kepala sekolah SPS Kenanga Dusun Gandekan, Ibu Kurniasari Pratiwi S.Psi.MA dan ibu Istri Bartini selaku tim pengabdian, mahasiswa yang tergabung dalam panitia pengabdian.terimakasih atas dukungan dan kerjasamanya dalam memberikan fasilitas luar biasa.

\section{Daftar Pustaka}

[1] Ditjen PAUDNI, Pedoman Pendidikan Karekter Pada Pendidikan Anak Usia Dini. Jakarta: Kemdiknas, 2011.

[2] Ditjen PAUDNI, Pedoman Penyelengaraan PAUD Berbasis Keluarga. Jakarta: Kemdiknas, 2011.

[3] (2011) Pentingnya Pendidikan Karakter dalam Dunia Pendidikan. [Online]. www.pendidikan karakter.com

[4] B Elizabet Harlock, Psikologi Perkembangan. Jakarta: Erlangga, 2015.

[5] Shochib, Pola Asuh Orang Tua dalam Membantu Anak Mengembangkan Disiplin Diri. Jakarta: PT. Rineka Cipta, 2010.

[6] Mudjiran Yona Yolanda, "Hubungan Pola Asuh Orang Tua dengan Komunikasi Interpersonal Siswa Dalam Proses Pembelajaran DiSekolah Dasar," Universitas Negeri Padang, Jurnal 2019.

[7] Khalid Abdurrahman, Pedoman Pendidikan Anak Menurut Al-Qur"an da Sunnah (Tarbiyatul Abna" wal Banat fi Dhau "il Kitab wa Sunnah). Surakarta: Al-Aqwam, 2010. 